\title{
Implementation of Microcontroller Based Distance Relay
}

\author{
Abubakar Isa, H. K. Verma, Abdurrahman Shuaibu, and Mubarak Auwal Saleh
}

\begin{abstract}
In this project microcontroller 8051 was used for comparisons between set Impedance and calculated Impedance for based distance relay of the protection of transmission line, based on that trip signal is send to circuit breaker. The Hardware consisted of main CT and VT, auxiliary VT and CT ,BLF ,sample and hold(S/H) circuit ,multiplexer ,ADC and microcontroller 8051.In which the main CT and VT step down the current and voltage respectably passed to auxiliary $\mathrm{CT}$ and VT for protecting the remaining components and convert the current into voltage in the output of auxiliary CT, then passed it to band limit filter to limit the frequency for sampling hold after sampling and hold circuit the signal is passed to multiplexer then to the ADC for analogue to digital conversion, after the conversion the digital signals is passed to the 8051 microcontroller to processing the signals that is calculating the average, impedance and compare it with the set impedance (store impedance) to generate trip signal when calculate impedance is less than or equal to set impedance. The trip signal is send to circuit breaker for tripping the first zone if condition is no it go to zone second zone and check the condition if yes trip is send to circuit breaker if no it go to third zone if yes trip and jump to initial point if not it go back to initial point. The relay software has been developed and simulated using Proteus software in which signal generator, ADC, microcontroller and LEDs are used for the purpose of checking fault in transmission.
\end{abstract}

Index Terms-Relay; Microcontroller; ADC; Proteus; Circuit Breaker.

\section{INTRODUCTION}

The power system protection performs the function of safeguarding the power system which include generation, transmission and distribution system from the fault s. The equipment need protection from fault otherwise, it can damage them and it will endanger people working around it. When fault occur at in a particular region the isolation of faulty region will ensure continuity of power to the healthy part, incurring minimum economic losses, to the users. This relay plays significant role in the operational security of system, the failure of which can lead to cascading failure effect. One of the reason for black out in northern region of India in 2008 have been improper setting of relay for zone III protection of transmission line [1].

This review tries to cover the various developments in digital relays for transmission line protection reported in the literature up to October 2010 and point to some of the references showing promising directions. Rockefeller first presented the implementation of digital relaying in 1969 [2].

Published on July 31, 2018.

A. Isa is with Sheda Science and Technology Complex, Abuja, Nigeria. (e-mail: abuabakarisa@yahoo.com).

H. K. Verma is with Sharda University Greater Noida, India.

A. Shuaibu is with Kampala International University, Uganda.

M. A. Saleh is with Kano University of Science and Technology,
The advances in the very large scale integrated (VLSI) technology and software techniques led to the development of microprocessor based relays that were first offered as commercial devices in 1979 [3].

\section{A. Digital relaying}

Relaying is branch of electric power engineering concerned with the principles of design and operation of equipment (called "relays" or protective relays") that abnormal power system conditions and initiates corrective action as quickly as possible in order to return the power system to its normal state by using digital techniques [4].

The quickness of response is an essential element of protective relaying system - response times of the order of few milliseconds are often required. Consequently, human intervention in the protection system operation is not possible. The response must be automatic, quick, and should cause a minimum amount of disruption to the power system [4].

\section{B. Impedance relay}

Impedance relay is used to measure as important quantity of the line i.e. measure parameter of the transmission line to the relay location. When abnormal condition occurs in transmission line impedance relay measures the line impedances as proportional to the length of the lines. The measured impedance value is less than the predefined value, than fault occurs in that section. In this relay the current compare with the voltage. In this relay current is measure by current transformer and voltage is measured by voltage transformer or potential transformer of the line [7]

\section{Organization of digital relay}

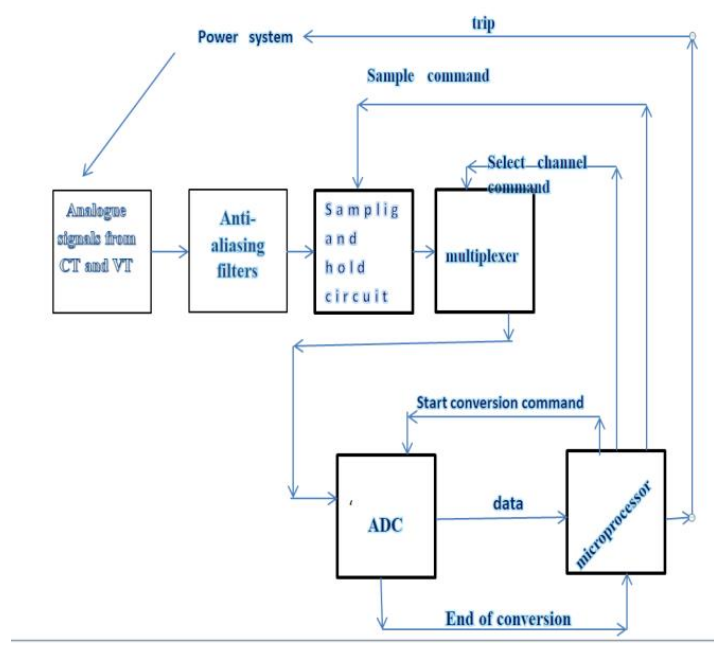

Fig. 1. Block diagram of numerical relay. [4]

Fig. 1. shows the block diagram shown above of numerical relay. Voltage Transformer and current 
Transformer signal cannot be sample directly and convert to digital form.

Therefore, the signals were first passed through a low pass filter, which has to be an analogue type of filter, because digital processing can only take place after the frequency spectrum of the signal is properly shaped.

Analogue signal is converted to digital form. The range of frequencies that can be handled by the analogue to digital converter without the sample and hold circuit $(\mathrm{S} / \mathrm{H})$ is extremely low. The $\mathrm{S} / \mathrm{H}$ value is pass to the ADC through a multiplexer so as to accommodate A large number of input Signals. The S/H circuit and the Analog Digital Converter work under the control of the 8051 microcontroller and Communicate with the help of Control Signal such as then of the conversion signal Issue by the analog Digital Converter. The Analog Digital Converter Passed. On digital representation of the Instantaneous value of the signal to the Microprocessor via an Input port. The wider the output of the ADC the greater the resolution [4].

The incoming digital value $\mathrm{S}$ from the ADC are Store in the RAM of the Microprocessor and processed by the relay software. In accordance with under, lying relay algorithms. The microprocessor issues the trips signal on one of the bit of its output port which is then suitable processed so as to make it comfortable with the trip coil of the circuit breaker. The microprocessor can also use to send information with other relays or another supervisory Computer, if so desired. The relaying program or the relay Software which reside in the EPROM can only be modified by authorized personnel [6].

Thus, new features and functionalities can be added existing relay by upgrading its Software. A numerical relay can be made to run a program which periodically performs a self-diagnostic test and issues an alarm signal if any difference is noted [6]. Other features like a watching dog timer can implemented, which issues an alarm if the microprocessor does not reset it, periodically, within a stipulated time. This gives an increased user confidence and improves the reliability of the relay.

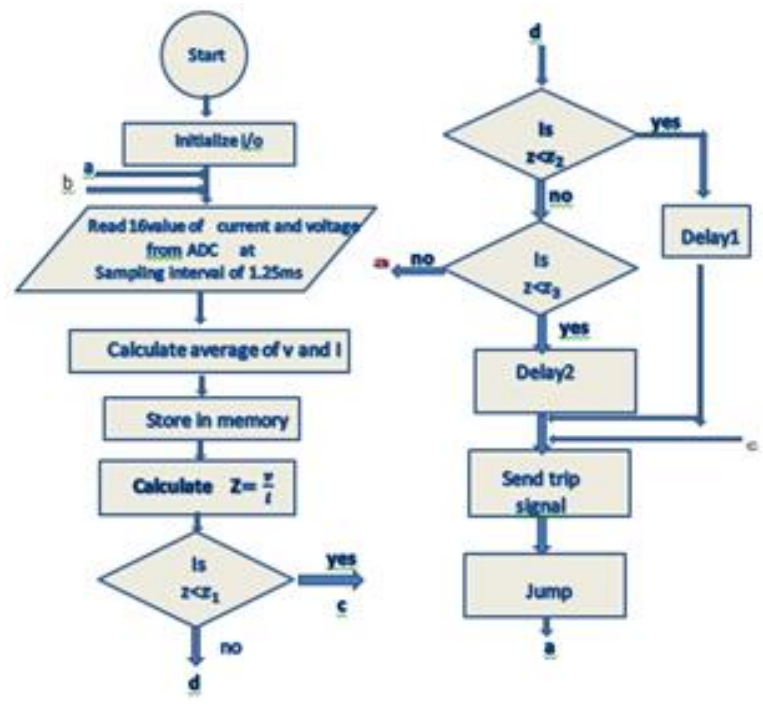

Fig. 2. Flowchart for Main Function

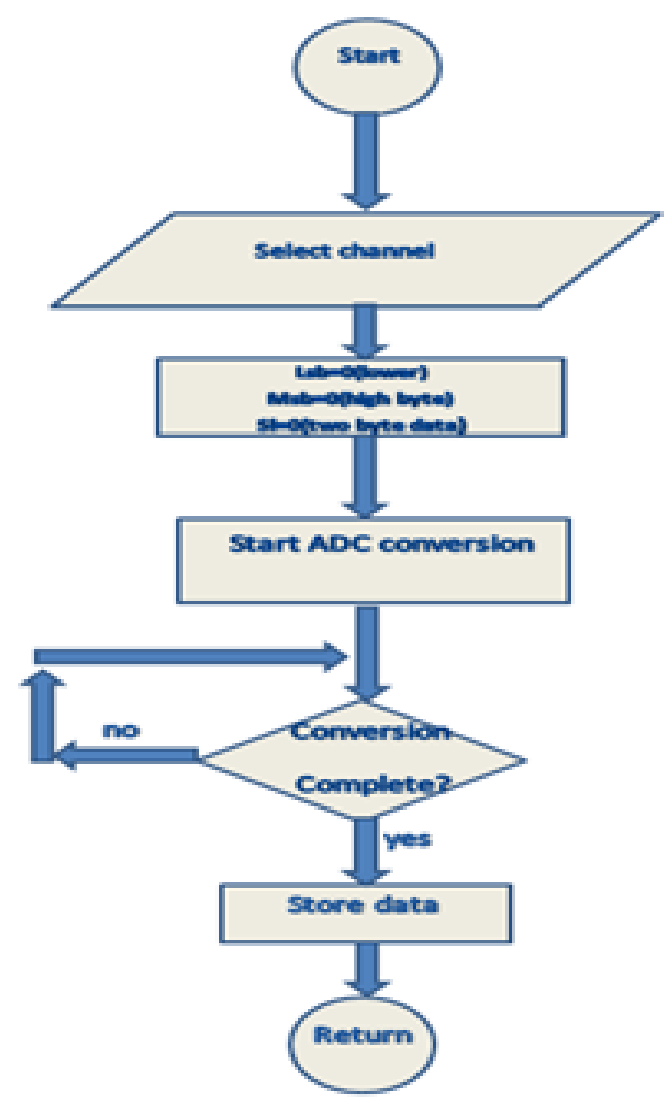

Fig. 3. Subroutine to read the ADC Channel

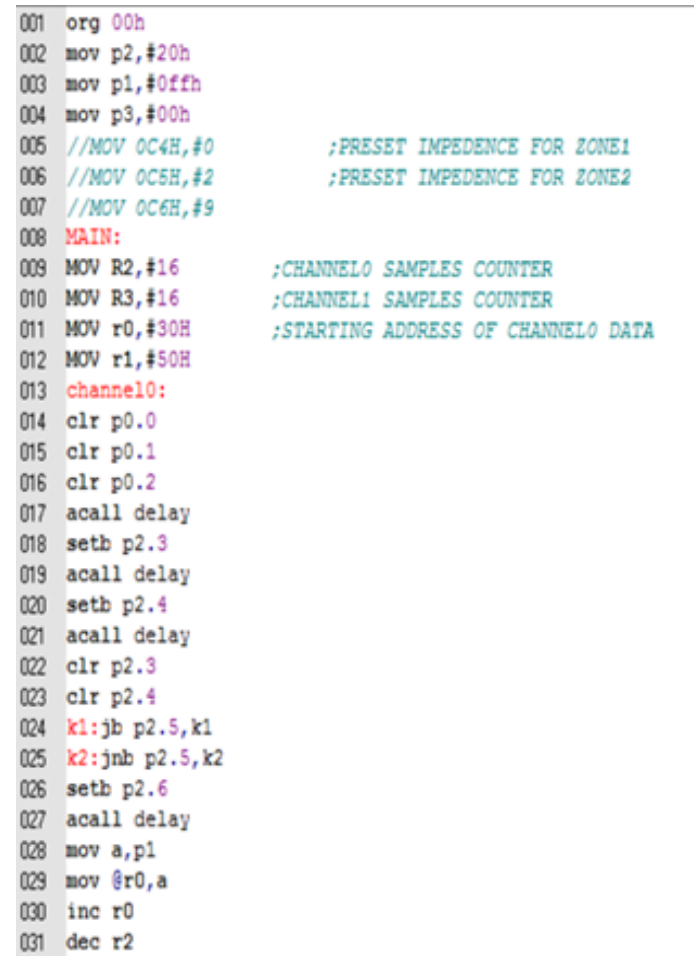

Fig. 4. Assembly Language Program

\section{HARDWARE SIMULATION}

The hardware simulation was did using proteus simulation software with these components VMS Signal Generator, AC Voltmeter, ADC0808,8051microcontroller and LEDs as shown in figure below. 


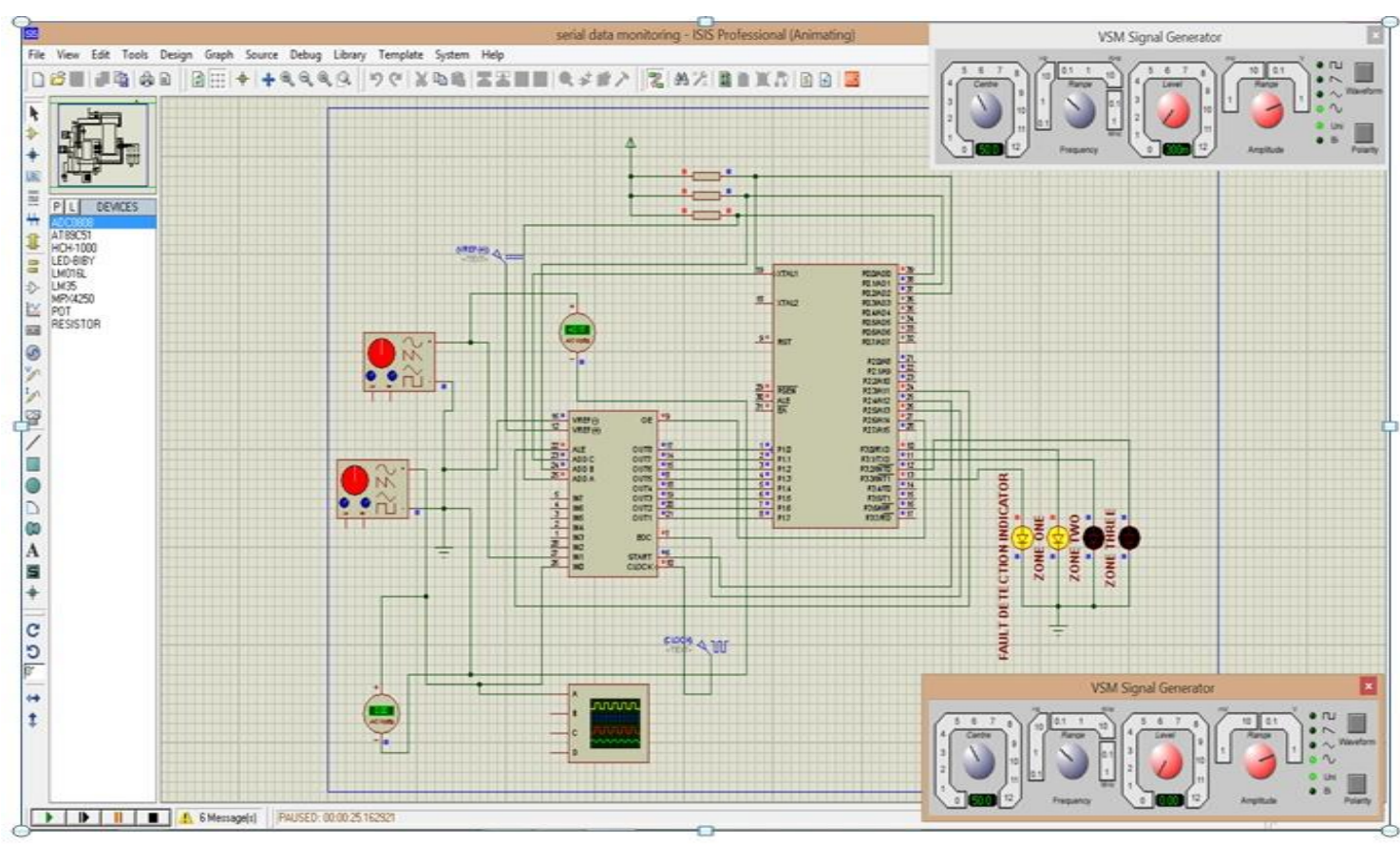

Fig 5. Hardware simulation

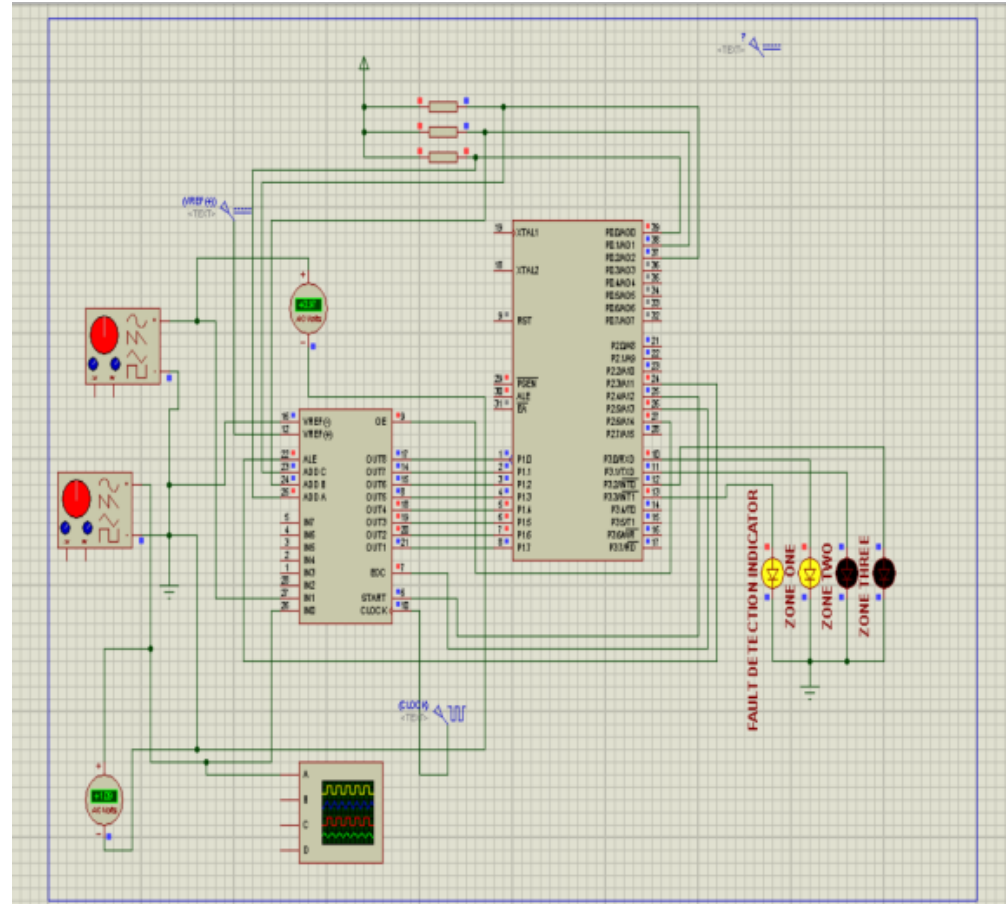

Fig. 6. Indicated and located fault at zone I 


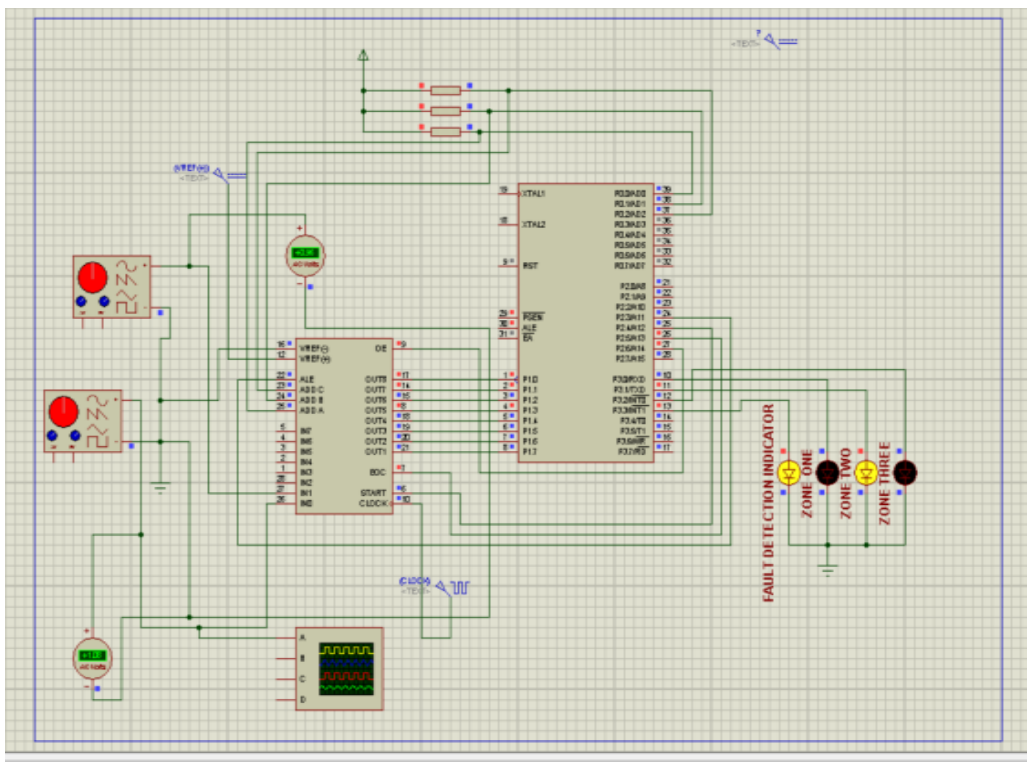

Fig. 7. Indicated and located fault at zone II

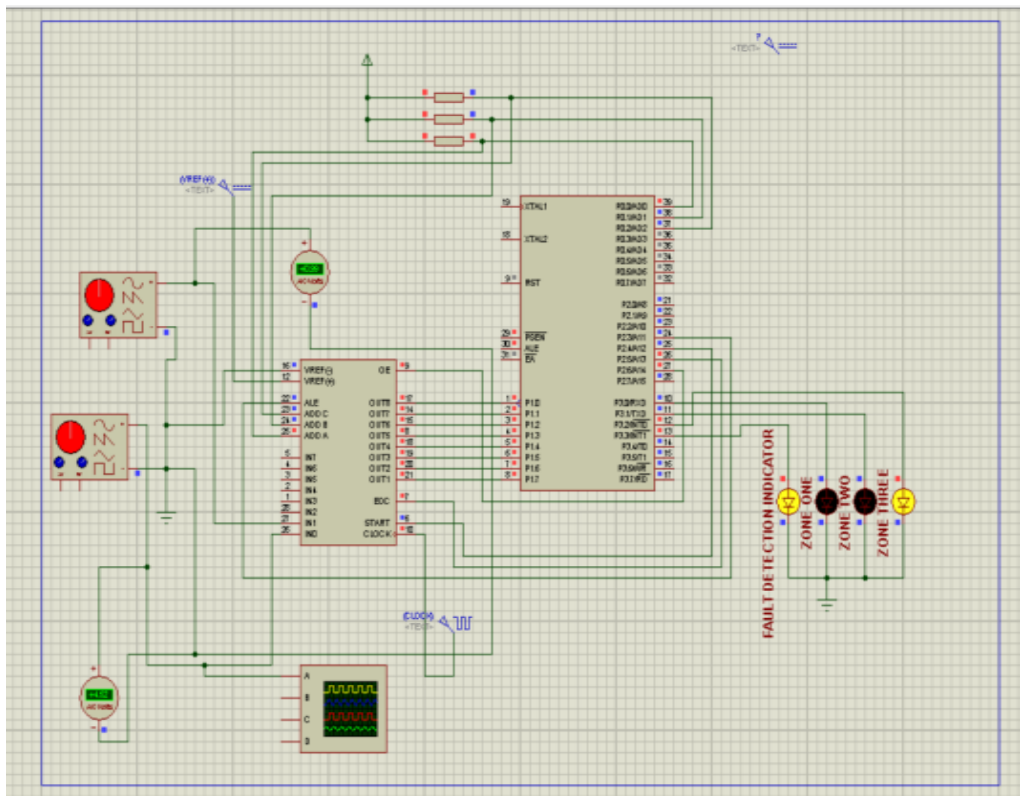

Fig. 8. Indicated and located fault at zone III

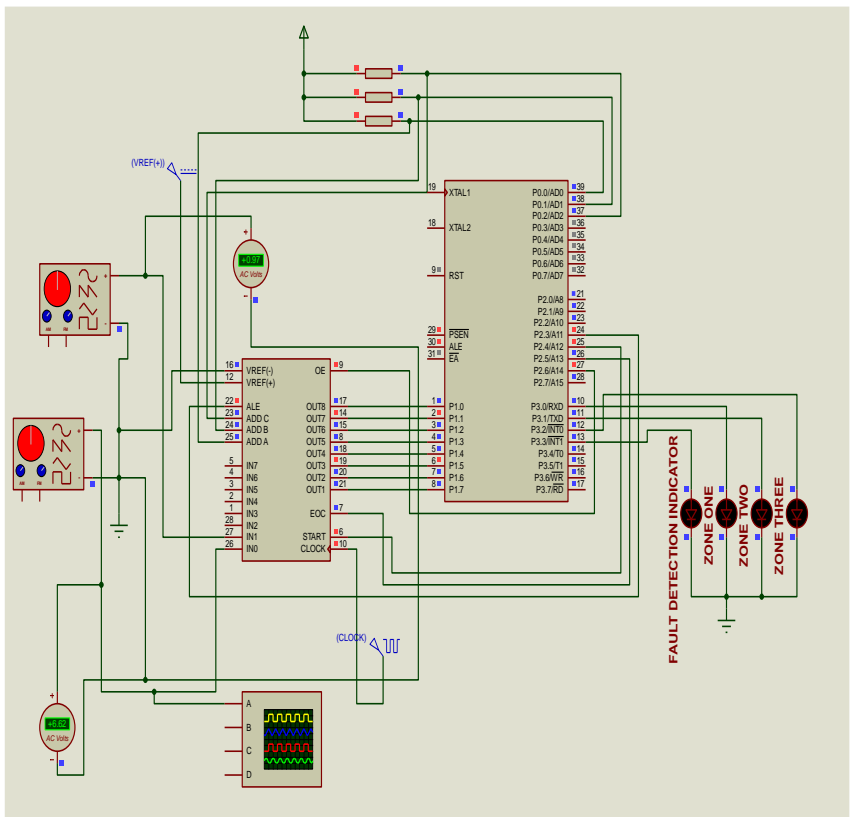

Fig. 9. No fault in all the three zones 


\section{RESULTS}

The impedance relay has been implemented using 8051 microcontroller and simulated in Proteus software. When the set impedance is greater than or equal calculated impedance LEDs is ON that is fault is detected in zone I, and trip signal is send to circuit breaker to trip zone I, if condition is no it go to zone second zone and check the condition if yes trip is send to circuit breaker if no it go to third zone if yes trip and jump to initial point if not it go back to initial point.

Zone I indicator LED is $\mathrm{ON}$ and one out of the three zones depending which zone the condition certified.

For zone $\mathrm{I}$ the set impedance is 2.The ratio of $v_{0} / v_{0}$ average is less than 2; LED one is ON, that is trip signal is send to circuit breaker in zone I and indicator (LED) is ON.

For zone II the set impedance is 3 . When the average value $\mathrm{Z}$ less set value LED 2 is $\mathrm{ON}$ and trip signal is send to circuit breaker in zone II. Similarly, for zone III the set impedance was compared with the calculated impedance based this the trip signal was to circuit breaker in Zone III. The result for calculated and set values impedance is tabulated below:

TABLE I: THE OUTPUT RESULTS

\begin{tabular}{lcccc}
\hline \hline Zone & Zone1 & Zone2 & Zone3 & \\
\hline$v_{0}$ & 0.99 & 0.99 & 0.97 & 0.97 \\
$x$ & 1.04 & 1.96 & 4.52 & 6.62 \\
\hline LED 1 & ON & OFF & OFF & OFF \\
LED 2 & OFF & ON & OFF & OFF \\
LED 3 & OFF & OFF & ON & OFF \\
LED indicator & ON & ON & ON & OFF \\
\hline \hline
\end{tabular}

\section{CONCLUSION}

The impedance relay algorithms are implemented using microcontroller 8051.The protection system has encouraged the development of microcontroller based relays. The relays are more accurate, fast, reliable and flexible compared to conventional relays.

\section{REFERENCES}

[1] L Mathew, L Shimi, and R. Thakur Recent Advanced and trends in Electrical engineering. New Delhi: Excel India publishers, 2014.

[2] Rockefeller G.D., 1969. Fault protection with a digital computer, IEEE Trans. Power App. and Syst., vol. 88, no.4, pp.438-464

[3] Sachdev M.S., (Coordinator), 1979. Computer relaying, IEEE Tutorial course text pub. 79EH01487-PWR.

[4] Muhammad Ali Mazidi and Rolin Mckinlay"the 8051 microcontroller and embedded system" publishing as Pretice Hall. 2006

[5] Stanley H. Horowitz and Arun G. Phadke" Power System Relaying Fourth Edition" This edition first published (c) 2014 John Wiley and Sons Ltd

[6] Singh L.P. "Digital protection -protective relaying from Electromechanical to Microprocessor" Willey Eastern Ltd.,1994

[7] H. A. McLaughlin, E. Erickson 'The Impedance Relay Developments and Application', Transactions a. i. e. July 1928.

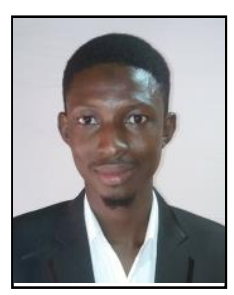

Abubakar Isa receive a B.Eng degree in Electrical Engineering from Kano University of Science and Technology, Nigeria in 2012, and M.Tech. Degree in Power System Engineering from Sharda University, Greater Noida India in 2015. Currently he is working with Sheda Science and Technology Complex, Abuja Nigeria.

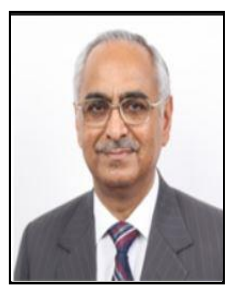

Prof. HK Verma Dean Academic Affairs Sharda University, Greater Noida India.

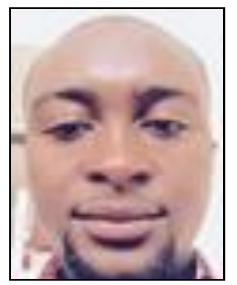

Abdulrahaman Shuaibu receive a B.Eng degree in electrical engineering from Kano University of Science and Technology, Nigeria in 2012, and $\mathrm{M}$.Tech. Degree in power system engineering from Sharda University , Greater Noida India in 2015. Currently he is working with kampala international University Uganda.

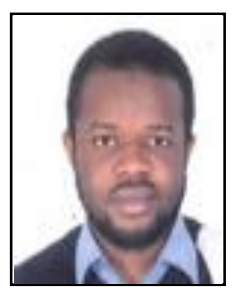

Mubarak Auwal Saleh receive a B.Eng degree in electrical engineering from Cope breton University Canada in 2012, and M.Tech. Degree in Control and Instrumentation Eengineering from Sharda University, Greater Noida India in 2015. Currently he is working with Kano University of Science and Technology, Nigeria. 